\title{
Dinâmica dos ajustes contratuais em concessão de rodovias no estado de São Paulo
}

\author{
Adriana Bortolon Carvalho Cardoso \\ Faculdade Estácio de Sá de Vitória \\ André Carlos Busanelli de Aquino \\ Faculdade de Economia, Administração e Contabilidade de Ribeirão Preto \\ Francisco Anuatti Neto \\ Faculdade de Economia, Administração e Contabilidade de Ribeirão Preto \\ Ricardo Lopes Cardoso \\ Escola Brasileira de Administração Pública e de Empresas
}

\begin{abstract}
A redefinição dos limites do Estado iniciada na década de 1990 no Brasil passou a incentivar ações de contracting-out nos diversos níveis da federação, expondo autoridades e especialistas à necessidade de discutir a dinâmica da regulação desses contratos que são intrinsecamente incompletos, dadas contingências não antecipáveis quando da negociação das condições e oferta. A concessão de rodovias em São Paulo foi estudada por meio de uma análise comparada das notificações e ajustes contratuais em 12 concessões de rodovias vigentes em 2006. Os dados triangulados com entrevistas realizadas na autoridade reguladora, a Agência Reguladora de Serviços Públicos Delegados de Transporte do Estado de São Paulo (Artesp), indicam que as renegociações encontradas não alteraram os termos gerais do contrato, mas sim o cronograma de obras e eventuais acréscimos de obras não previstas no programa original, preservando o equilíbrio financeiro inicial do contrato.
\end{abstract}

Palavras-chave: concessão rodoviária; regulação; ajuste contratual; renegociação.

Dinámica de la enmienda en los contratos de concesión de autopistas en el estado de São Paulo La reforma del Estado de Brasil se inició en los años 1990 alentó a la contratación externa en los distintos niveles de la federación, las autoridades de peso y expertos para discutir la necesidad de una regulación dinámica de estos contratos. Contratos a largo plazo son inherentemente incompletos, dado que las condiciones comerciales y de suministro están sujetos a contingencias imprevisibles. Los contratos de concesión de autopistas del Estado de São Paulo fueran estudiados a través de un análisis comparativo de las notificaciones y las modificaciones contractuales de 12 contratos en vigor en 2006. La interpretación de los datos se comprobó con entrevistas a la autoridad reguladora (Artesp).

Artigo recebido em 12 set. 2011 e aceito em 18 jul. 2012.

Rev. Adm. Pública - Rio de Janeiro 46(5):1295-315, set./out. 2012 
La conclusión es que las renegociaciones no modificaran los términos generales de los contratos, pero lo hizo para cambiar la programación de las obras y compensar por trabajo acumulado no previsto en el programa original, con el objetivo de preservar el equilibrio financiero inicial del contrato.

Palabras clave: concesión de autopista; regulación; modificaciones contractuales; renegociación.

Dynamics of contractual amendments on highway concession from the state of São Paulo The Brazil State reform started in the 90s encouraged contracting out at various levels of the federation, compelling authorities and experts to discuss the need for dynamic regulation of these contracts. Long Term contracts are inherently incomplete, given that trading conditions and supply are subject to unpredictable contingencies. The Sao Paulo Highways concessions case is studied through a comparative analysis of notifications and contractual amendments of 12 highway concession contracts in force in 2006. The interpretation of data was checked with interviewing regulatory authority (Artesp). The conclusion is that renegotiations did not change the general terms of the contract, but did to change the schedule of works and some accrued work not stipulated in the original program. Changes in contract terms were guided by preserving the initial financial equilibrium of the contract.

KEY WORDs: highway concession; regulation; contractual amendments; renegotiation.

\section{Introdução}

Até o final da década de 1990 a expansão e manutenção das rodovias era responsabilidade exclusiva do poder público, que operava por meio de secretarias ou departamentos (estaduais ou federais, dependendo da rodovia) na contratação direta dos prestadores de serviço (na maior parte, empreiteiras), e os custos eram financiados também diretamente pelo poder público, por meio da cobrança de tributos, principalmente impostos, e, em casos excepcionais, taxas - como o "selo pedágio" que vigorou no final da década de 1980 (instituído pela Lei n⿳o 7.712/1988 e extinto pela Lei no 8.075/1990).

A partir da implementação, no Brasil, de iniciativas inspiradas no Anglo-Saxon Third Way (Bresser-Pereira e Grau, 1999) e, especificamente, no movimento conhecido por New Public Management, o poder público mudou seu posicionamento, deixando de prestar diretamente determinados serviços públicos, que foram delegados a entidades não governamentais e empresas privadas (Brinkerhoff e Brinkerhoff, 2002; Oliveira e Tandon, 1994; Selsky e Parker, 2005; Paula, 2005).

Entre os diversos serviços públicos delegados à iniciativa privada nesse período, tem-se a expansão, manutenção e operação de rodovias (principalmente intermunicipais e interestaduais). Nesse contexto, quando viável, o poder público deixaria de prestar diretamente o serviço e passaria a monitorar o serviço prestado pelas concessionárias. Os dois principais aspectos desse monitoramento envolvem a fiscalização do cumprimento dos compromissos assumidos e a regulação tarifária.

As tarifas fixadas para os contratos de concessão licitados a partir de 1995, sob a égide da lei de concessões, seguiram a proposta vencedora da licitação, cujo valor deve ser preser- 
vado pelas regras de revisão previstas no edital e no contrato. Essa premissa legal faz com que o regime tarifário que rege esses contratos seja o de teto tarifário ou price-cap, que se contrapõe ao regime de retorno assegurado do investimento ou rate-of-return, que mantém taxa de retorno constante definida em contrato. A tarifa definida pelo price-cap gera maior incentivo para que as concessionárias controlem seus custos. Efeito contrário ocorre no do regime de taxa de retorno, em que os aumentos de custos são repassados aos preços para manter a lucratividade, que é fixada. No price-cap o concessionário assume maior parcela dos riscos operacionais.

As concessões de serviços de transporte rodoviário mais comuns na América Latina têm sido do tipo build-operate-transfer (BOT) (Guasch, 2004), que equivalem em termos gerais ao mecanismo clássico de concessão para exploração, construção e prestação de serviço por um período determinado, ao fim do qual o projeto retorna ao Estado. O mesmo estudo constatou que os contratos de concessão desses países são predominantemente: price-cap (56\% das concessões), regimes híbridos (24\%) e rate-of-return (20\%). Guasch (2004) analisou com que frequência os contratos de concessão passaram por renegociações após serem licitados e identificou que $83 \%$ dos contratos baseados em price-cap passaram por renegociação, e que, na maior parte, as renegociações foram iniciadas pelas concessionárias. Ao passo que entre os demais contratos de concessão rodoviária na América Latina, pouco mais de metade dos contratos passou por renegociações em período médio de aproximadamente três anos após o início de vigência (Guasch, 2004).

A análise do contexto brasileiro precisa considerar que, embora a malha de rodovias pavimentadas no Brasil seja superior a 216 mil quilômetros, menos de um décimo dela é operada por meio de concessões federais ou estaduais. As experiências e modelos de concessão de transporte rodoviário no Brasil foram avaliadas em Oliveira, Michel e Cydis (2004), que consideraram a primeira rodada de concessões federais, as experiências dos programas estaduais do Rio Grande do Sul, Paraná e São Paulo. Em comum, todos os contratos passaram por processos licitatórios, em que os editais previam um plano de negócios com exigências de investimentos, e a execução dos planos de negócios pautava os principais compromissos assumidos pelos concessionários. O monitoramento da execução desses contratos passou a ser realizado por reguladores independentes nos estados do Rio Grande do Sul e de São Paulo e para os contratos federais, a partir de 2002, foi criada a Agência Nacional de Transporte Terrestre (ANTT).

Os contratos de concessão são contratos incompletos e os investimentos realizados na concessão são em sua maior parte investimentos em ativos específicos, dedicados a uma determinada operação (Besanko et al., 2006). A existência de investimentos irrecuperáveis dá espaço à ação oportunista, uma vez que o poder concedente tem o controle sobre as tarifas e pode reduzi-las em termos reais, impedindo que os investimentos possam ser recuperados ao seu custo de oportunidade (efeito hold up). A incompletude contratual pode permitir tal expropriação de valor por meio de exploração de brechas contratuais (Milgron e Roberts, 1992; Klein, 1999). Essa situação pode ser reduzida caso exista forte dependência bilateral, ou seja, cada parte depende da contraparte (Brousseau e Fares, 2000). 
Especificamente no caso dos contratos de concessão no Brasil, o regime de atribuição de direitos, com intuito de defender o interesse público, reserva ao poder concedente direito de alteração unilateral do contrato (chamadas de cláusulas exorbitantes). Por outro lado, a lei procura preservar a expectativa de ganho do concessionário ao estabelecer que, "Em havendo alteração unilateral do contrato que afete o seu inicial equilíbrio econômico-financeiro, o poder concedente deverá restabelecê-lo, concomitantemente à alteração". ${ }^{1}$

Nesse sentido, ao separar papéis do poder concedente e das agências reguladoras, pautadas pela competência técnica e autonomia decisória, se introduz um elemento mitigador de riscos associados aos investimentos específicos feitos pela concessionária. A presença de um órgão regulador autônomo permite que as pressões de várias ordens, a que os titulares do poder concedente estão sujeitos, encontrem a fundamentação técnica para determinar as bases para a recomposição do equilíbrio econômico-financeiro.

Na terminologia de Guasch (2004), renegociação é a expectativa de que mudanças nas condições de execução do contrato possam restituir a expectativa de lucratividade. Nesses termos, as renegociações, embora não desejáveis, podem ser encaradas como decorrentes do ambiente de incertezas presentes no momento em que os contratos são firmados e de contingências que podem ocorrer durante a execução do contrato (Tirole, 1999; Hart e Moore, 1988). Mesmo que muitas das contingências pudessem ser incluídas no contrato, de tão numerosas que são, o custo de descrevê-las não compensaria o esforço ex ante ou evitaria a necessidade de adaptações (Tirole, 1999). Isso sugere a necessidade de renegociações (Stern, 2003), por isso as partes mantêm direitos residuais de controle, que permitam a adoção de decisões discricionárias ex post.

Este estudo apresenta e analisa a dinâmica de interação na proteção contra expropriação de excedentes por imposições de obrigações adicionais às concessionárias de serviços delegados de operação, conservação e ampliação do sistema rodoviário do estado de São Paulo. Foram analisados 12 contratos em vigor no ano de 2006, com interesse específico nas negociações conduzidas pela Agência Reguladora de Serviços Públicos Delegados de Transporte do Estado de São Paulo (Artesp). Esses contratos de concessão previam contingências como alterações de alíquotas de impostos, mudanças de capacidade de oferta ou nível de qualidade de serviço e suas implicações em traçados de pista, duplicações, entre outras, acabariam por gerar necessárias adequações. Essas adequações, por sua vez, seriam objeto de ajuste entre as partes.

A análise das renegociações baseou-se em dados anuais de ajustes em investimentos realizados pelas concessionárias e no número anual de notificações recebidas por concessionárias. Os dados foram coletados pela primeira autora por meio de exame de documentos físicos e eletrônicos, observação direta, triangulados com entrevistas semiestruturadas com executivos da agência reguladora Artesp, no período entre janeiro de 2006 e janeiro de 2007, tendo sido realizadas três incursões à Artesp, incluindo suas áreas de fiscalização e consultoria. Uma entrevista foi conduzida junto ao grupo OHL para análise do ponto de vista da concessionária.

\footnotetext{
${ }^{1}$ Art. 9o, parágrafo 4ํำ da Lei no 8.987/1995.
} 
O artigo é divido em cinco seções, incluindo esta introdução. Na segunda, apresenta-se breve histórico da regulação de rodovias no estado de São Paulo e a agência reguladora. Na terceira seção é desenvolvida análise da dinâmica dos ajustes realizados nos 12 contratos de concessão. A quarta seção apresenta a análise empírica dos ajustes contratuais. A última seção apresenta as considerações finais.

\section{0 modelo de concessão de rodovias do estado de São Paulo e Artesp}

No estado de São Paulo as concessões seguem o marco regulatório definido no Programa Estadual de Desestatização, criado pela Lei no 9.361/1996, que serviu de instrumento à implantação do Programa de Concessões Rodoviárias do Estado. O programa de concessão é constituído por um contrato firmado entre a firma vencedora do processo licitatório e o Governo do Estado de São Paulo, por intermédio do Departamento de Estradas de Rodagem/SP (DER/SP).

O Governo do Estado de São Paulo, em seu planejamento interno, decidiu por 12 lotes como prioridade de concessão, dada a potencial viabilidade econômica (volume de tráfego e projeção de arrecadação) estudada pela Comissão de Monitoramento ${ }^{2}$ (Monteiro, 2005). Esses lotes somam $3.545 \mathrm{~km}$, atendem 167 municípios, 20 milhões de pessoas, ou 54\% da população do estado. A partir dessa definição, o grupo de técnicos que compôs a equipe governamental iniciou a redação dos editais, supervisionada pela Procuradoria-Geral do Estado e juristas. Tal edital seguiu a Lei da Licitação, contemplando todas as regras e condições da concorrência; no caso de São Paulo, foram 12 concorrências internacionais (Recchi, 2005). Em 1997, foram realizadas as licitações, as quais exigiram que as concorrentes apresentassem a metodologia detalhada de execução técnica de obras e serviços, assim como a proposta financeira com o valor que o licitante estava se propondo a pagar ao estado de São Paulo pelo direito de exploração das rodovias, demonstrando todo o fluxo financeiro previsto (Recchi, 2005).

Os contratos detalham as regras básicas do edital e regulam minuciosamente toda a execução do programa, especificando obras e serviços a serem executados e condições que as concessionárias devem cumprir, durante todo o prazo de concessão (Recchi, 2005). O contrato de concessão prevê as amarras para que se garanta seu cumprimento por parte da concessionária e da Agência, visto que toda a formalidade de execução está sustentada por uma política regulatória. As concessionárias ficam responsáveis por serviços de conservação e obras de expansão. Sendo que serviços de conservação e rotina incluem pavimentação, drenagem e sinalização, e obras de expansão são as previstas no cronograma físico, com todos os detalhamentos de datas de realização. Os primeiros nove contratos foram assinados no ano de 1998 e os três demais foram assinados em 2000.

\footnotetext{
${ }^{2}$ A Comissão de Monitoramento das Concessões e Permissões de Serviços Públicos foi criada através do Decreto-lei no 43.011/98 para acompanhar e fiscalizar os serviços delegados de transporte.
} 
A Artesp foi criada como uma autarquia ${ }^{3}$ vinculada à Secretaria dos Transportes, por meio da Lei Complementar no 914, de 14 de janeiro de 2002, sendo atribuída a essa Agência a tarefa da execução, gestão e fiscalização dos serviços delegados, ${ }^{4}$ apoio na execução dos serviços não delegados ${ }^{5}$ e gestão e fiscalização dos serviços complementares. ${ }^{6}$ A malha rodoviária paulista (23 mil quilômetros) foi fragmentada em 22 lotes, ${ }^{7}$ e apenas 12 desses lotes haviam sido concedidos à iniciativa privada até 2006.

A Artesp exerce suas funções junto às concessionárias das rodovias por meio de empresas de apoio à fiscalização (EAFs) e de empresas de apoio ao gerenciamento (EAG). A EAG presta serviços técnicos especializados de consultoria, assessoramento, planejamento e apoio técnico para o gerenciamento, acompanhamento e controle de todas as etapas do programa de concessão, assim como apoia a Artesp no desenvolvimento de ações conjuntas entre as concessionárias e EAFs visando à padronização das informações fornecidas pelas concessionárias (Artesp, 2006).

As EAFs são prestadoras de serviços de fiscalização e acompanhamento das concessionárias. A Artesp contrata um agente fiscalizador para cada concessionária. A contratação se dá por meio de licitação, por período de dois anos, renováveis por mais dois anos. Tal acompanhamento é feito semanalmente e segue diretrizes da Artesp, envolvendo: (i) identificação de todos os serviços a cargo das concessionárias, nas áreas de projetos, obras de ampliação e melhoramentos, operação, conservação, comunicação social e assuntos ambientais; (ii) operacionalização dos procedimentos de fiscalização e controle, com a padronização de formulação, formato, veiculação e registro de informações prestadas pelas concessionárias; (iii) análise, com base nos dados obtidos na fiscalização, das causas e tendências de desvios da atuação da

\footnotetext{
${ }^{3}$ O Decreto-lei no 239 de 21 de julho de 1975 define autarquia como "serviço autônomo criado por lei, com personalidade jurídica de direito público, patrimônio e receita próprios, para executar atividades típicas da Administração Pública, que requeiram para seu melhor funcionamento gestão administrativa e financeira descentralizada". As autarquias têm patrimônio formado por recursos próprios. Sua organização interna pode vir por meio de decretos (emanam do poder executivo), de portarias (ministérios, secretarias), regimentos ou regulamentos internos.

${ }^{4}$ Serviços delegados são aqueles que devem ser prestados obrigatoriamente e ininterruptamente pela concessionária durante todo o prazo da concessão. São os serviços, ligados à operação, conservação e ampliação do sistema rodoviário.

${ }^{5}$ Serviços não delegados são aqueles de competência exclusiva do poder público e, portanto, não são objetos da concessão. Entre eles estão: o policiamento ostensivo de trânsito, preventivo e repressivo; a fiscalização e autuação de infrações; emissão de outorgas a serviços de transporte coletivo, escolar, de trabalhadores rurais, de cargas excepcionais e perigosas e realização de eventos na rodovia.

${ }^{6}$ Serviços complementares são aqueles considerados convenientes, mas não essenciais para manter o serviço adequado, devendo ser prestados por terceiros, que não a concessionária, como abastecimento e reparo de veículos, alimentação e hospedagem para usuários e provisão de áreas de lazer e repouso para usuários.

${ }^{7}$ A Lei no 9.277/1996 possibilitou à União delegar aos estados a administração e a exploração de trechos de rodovia ou obras rodoviárias. Portaria nº 368/1996 do Ministério dos Transportes definiu os procedimentos para a delegação, ficando o DNER com a coordenação e a fiscalização da execução. Essa iniciativa acabou trazendo um tratamento mais sistêmico (de malha) aos trechos concedidos, introduzindo o conceito de lotes, em contraposição à experiência federal, onde as rodovias eram tratadas de forma isolada.
} 
concessionária em relação ao contrato de concessão e aos procedimentos fixados pela Artesp; (iv) acompanhamento de todos os eventos contratuais, de responsabilidade da concessionária (Artesp, 2006). Identificadas não conformidades, as EAFs emitem relatórios específicos (relatório de não conformidades e relatório fotográfico) e encaminham à fiscalização da Artesp via e-mail, com cópia para a concessionária correspondente, a fim de que a mesma inicie as correções (Artesp, 2006).

A Artesp recebe uma parcela variável correspondente a 3\% da receita bruta efetivamente obtida pela concessionária no mês anterior ao pagamento. Os valores são pagos mensalmente de acordo com a demanda de cada trecho pedagiado. A remuneração das empresas de apoio (EAFs e EAG) se dá por valor fixo mensal, sendo reajustado anualmente por um índice específico que, segundo Informações da Agência, equipara-se ao Índice Nacional de Preços ao Consumidor (INPC) (Artesp, 2006).

A concessionária paga ao estado, representado pelo DER/SP, um valor fixo definido na proposta. Por exemplo, no caso da concessionária Renovias, pelo estipulado no contrato 004/CR/1998, o ônus devido ao estado alcançou um total de R $\$ 151$ milhões, a ser pago em 240 parcelas mensais. As oito primeiras parcelas correspondem a 0,9\% do valor total e as 232 restantes correspondem a $0,4 \%$ do valor total. O reajuste das parcelas ocorre nas mesmas datas dos reajustes aplicados à tarifa de pedágio.

A remuneração das concessionárias em questão, seguindo o estabelecido nos contratos, vem da cobrança da tarifa de pedágio e, também, de fontes acessórias de receitas, entre elas: rendimentos decorrentes de aplicações financeiras e cobrança por publicidade (Governo do Estado de São Paulo, 2003).

\section{A dinâmica dos ajustes contratuais}

Contratos de concessão são contratos de longo prazo e podem ser considerados contratos incompletos de acordo com a teoria econômica dos contratos (Martimort, 1999; Guasch, 2004). No contexto dos contratos incompletos, mesmo que se assuma que as partes têm a mesma informação ex ante à assinatura do contrato, admite-se que demandarão ajustes durante a execução do contrato diante da existência de contingências futuras que não são antecipáveis quando da celebração do contrato (Furubotn e Richter, 2000). Tais ajustes são necessários como medidas adaptativas às circunstâncias não previstas ou previsíveis, mas com consequências não quantificáveis, para manter o equilíbrio de direitos pactuados ex ante. A necessidade de adaptar o contrato às contingências não previstas demanda adaptações ex post, e tais ajustes representam custos de transação adicionais (Williamson, 1991).

Os contratos de concessão em análise preveem o direito ao reequilíbrio em função de incidência de riscos não alocados aos concessionários. Os riscos explicitamente alocados ao concessionário, e que não dão direito ao reequilíbrio, são: o risco de tráfego (demanda); o risco de construção, principalmente quanto à conclusão das obras nos prazos previstos no con- 
trato; o risco de variações de custos e variações em preços de insumos; e o risco das projeções das receitas acessórias, pois sua assunção pela concessionária foi integral.

Por outro lado, o direito ao reequilíbrio protege as concessionárias de riscos que não são capazes de evitar, de se proteger e mitigar. O principal deles é aquele associado ao direito residual do poder concedente de modificar unilateralmente o contrato. Esse direito está associado ao caráter público da concessão e ao controle sobre ela delegado ao Poder Executivo (Mello e Anuatti, 2001). Da mesma forma, o ambiente macroeconômico instável em que os contratos foram celebrados incluiu salvaguardas relativas a significativas modificações nos mercados financeiro e cambial, que impliquem alterações substanciais nos pressupostos adotados na elaboração das projeções financeiras. Preservam-se ainda, sob o título de casos de força maior ou de eventos excepcionais, as circunstâncias imprevisíveis e de consequências incalculáveis e alterações legais de caráter específico, que tenham impacto significativo e direto sobre as receitas ou sobre os custos.

A atribuição da Artesp é monitorar a ocorrência dos riscos ao longo da concessão e garantir a execução do contrato. O contrato de concessão garante ao poder concedente o direito discricionário de rever o cronograma e o escopo das obras a serem realizadas. A concessionária, por sua vez, solicita compensação caso essas alterações tenham efeito sobre o equilíbrio inicialmente pactuado.

Mesmo que não sejam feitas alterações no escopo das obras, a mera alteração do cronograma de execução pode suscitar o reequilíbrio econômico-financeiro. Se os atrasos em relação ao cronograma fixado na proposta, mesmo que justificados, decorrerem de riscos atribuídos aos concessionários, pelo seu efeito de postergação de investimentos, deveria contribuir para a redução de tarifa. Da mesma forma, antecipações requeridas pelo poder concedente teriam efeito de aumento tarifário. Se o ajuste não se der por meio de variação tarifária, poderá ocorrer por meio de outras compensações de dilatação de prazo de outras obras, abatimento do ônus ou prorrogação de prazos contratuais.

Com o potencial dos mesmos efeitos, mas com natureza formal distinta, encontram-se os ajustes associados à inclusão de obras não previstas no plano de negócio. Num ambiente de contratos incompletos é razoável que, diante de circunstâncias não previstas por ocasião da licitação, novas obras venham a se tornar demandas legítimas dos poderes públicos estadual e locais. Muitas vezes, a solução mais adequada será a de atribuir tais obras à concessionária ao invés de promover contratação isolada das mesmas. Diferentemente dos ajustes de cronograma, essas obras não têm valor previsto no plano de negócios, tornando o processo de reequilíbrio mais complexo, mesmo que os instrumentos de reequilíbrio continuem os mesmos.

Ajustes contratuais são necessários também quando do surgimento de impostos não previstos e devidamente computados por ocasião da licitação. O risco tributário é atribuído ao poder concedente, sendo necessário que os efeitos da introdução de um novo imposto sejam compensados, para que a tarifa após impostos volte a garantir as condições anteriores.

Uma questão mais controversa está associada ao risco de desvio das praças de pedágio. Em princípio, o risco de demanda é alocado à concessionária. Esse risco inclui a elasticidade de preço dos usuários, de modo que, se uma tarifa for demasiadamente elevada ao ponto 
de induzir usuários a buscarem rotas alternativas, essa seria uma típica reação de mercado. Como as concessões foram realizadas empregando-se praças de pedágio existentes, a implantação da cobrança teve como efeito o surgimento de rotas de fuga, com a intensificação do trânsito local, e congestionamento de vias secundárias. Assim, existiriam efeitos externos da cobrança de pedágios que recairiam sobre o poder público.

Nesse sentido, tornar o sistema de cobrança mais eficiente seria uma forma de mitigar tanto os efeitos sobre as receitas das concessionárias como de minorar os efeitos negativos das rotas de fuga. Assim, como exemplos de ajustes que foram realizados para diminuir o impacto da cobrança sobre os usuários, podem ser destacados a implantação de praças bidirecionais e a realização de obras para separação de vias expressas de vias locais.

Outra forma de mitigar os impactos da cobrança das tarifas sobre os usuários foi o ajuste, adotado por iniciativa do poder concedente, que impediu a aplicação integral do índice de correção contratual das tarifas. Tal medida, embora tenha amortecido os efeitos da aceleração dos índices de correção sobre as tarifas pagas pelos usuários em determinado período, ocasionou a necessidade de que a Artesp promovesse a recomposição do equilíbrio econômico financeiro dos contratos.

Para apurar os efeitos de tais ajustes sobre o equilíbrio econômico-financeiro, a Artesp adotou, como procedimento geral, a sua representação no fluxo de caixa do Plano de Negócios original. Os efeitos líquidos do ajuste seriam apurados em valor presente na data do contrato descontado pela taxa interna de retorno (TIR) original. O equilíbrio econômicofinanceiro seria restabelecido por meio de medidas compensatórias como adiamento/antecipação do cronograma de obras, redução do ônus, aumento/diminuição do prazo de contrato, aumento/diminuição nas tarifas.

Ao adotar esse critério, garantindo a manutenção da TIR inicial, a Artesp buscava reduzir a incerteza da concessionária quanto ao desempenho futuro do contrato, preservando a reputação de neutralidade, ao mesmo tempo que eram atendidas as alterações solicitadas pelo governo (ajustes).

Por outro lado, a Artesp precisa também lidar com os incentivos da concessionária na redução de custos que comprometam a eficiência nos serviços e com os incentivos de informar custos acima dos reais nas negociações de ajustes. Para cumprir esse papel fiscalizador e garantir a eficiência dos serviços, a Artesp dispõe de poder regulatório e conta com as EAFs e a EAG. A ação fiscalizatória se inicia pela emissão de notificações diante de irregularidades e não conformidades identificadas na operação das rodovias ou no cumprimento do cronograma de obras. Se os requisitos contratados não são realizados pela concessionária após a notificação, as penalizações podem evoluir de advertências para multas.

\section{Análise empírica dos ajustes contratuais}

O presente estudo se utilizou da análise de documentação física e eletrônica e coleta de dados

produzidos pela Empresa de Apoio ao Gerenciamento. Os dados secundários coletados, para 
o período de janeiro de 2006 a janeiro de 2007, foram obtidos dos documentos físicos e eletrônicos da Artesp, sendo predominantemente quantitativos.

A tabela 1 apresenta as 12 concessionárias, sua extensão em quilômetros e a demanda média observada no período de 1999 a 2006. Estão representadas em itálico as três concessionárias licitadas em 2000, as demais foram licitadas em 1998. A extensão média dos lotes licitados é próxima a $300 \mathrm{~km}$ e o porte das concessões pode ser avaliado pelo volume de veículos diário médio (VDM). As concessionárias estão ordenadas em ordem decrescente de VDM, destacando-se o maior porte das três primeiras.

Tabela 1

Concessionárias - extensão e demanda da malha operada

\begin{tabular}{|cccc|}
\hline Concessionárias & Malha viária (km) & VDM (*) & VDM/km(**) \\
\hline Autoban & 315,9 & $42.214,7$ & 133,6 \\
Ecovias & 176,9 & $40.750,1$ & 230,4 \\
Viaoeste & 162,4 & $37.944,8$ & 233,6 \\
Colinas & 299,0 & $13.185,2$ & 44,1 \\
Centrovias & 218,2 & $10.280,5$ & 47,1 \\
Vianorte & 236,6 & $9.869,1$ & 41,7 \\
Renovias & 345,4 & $8.190,7$ & 23,7 \\
Intervias & 375,7 & $7.209,1$ & 19,2 \\
Triângulo do Sol & 442,2 & $7.073,5$ & 16,0 \\
Autovias & 316,5 & $7.036,9$ & 22,2 \\
SPVias & 505,7 & $6.173,7$ & 12,2 \\
Tebe & 156,0 & $3.695,4$ & 23,7 \\
\hline Fonte: Artesp (2006). & & & \\
Concessionárias marcadas em itálico foram licitadas em 2000, as demais foram licitadas \\
em 1998.
\end{tabular}

A última coluna da tabela 1 apresenta a razão veículos diários médios por quilômetro, que representa uma razão entre o potencial de arrecadação e os custos de operação e manutenção. Nota-se também a disparidade das três primeiras na tabela (em VDM/km) em relação ao restante das concessões, indicando que essas concessões teriam um potencial muito maior de investimentos a serem realizados.

A tabela 2 apresenta a razão entre as demandas previstas nos editais de licitação e as demandas verificadas no ano de 2002. O ano foi escolhido por ser o primeiro que permite a 
comparação de todas as concessionárias, dado que três delas foram licitadas em 2000 (concessionárias destacadas em itálico). Nota-se que oito concessionárias apresentaram demandas abaixo das previstas em edital. Essa situação é conhecida na literatura como viés de otimismo dos agentes públicos nas avaliações de projeto. Flyvbjerg, Holm e Buhl (2005) avaliaram 210 projetos de infraestrutura de transportes desenvolvidos entre 1969 e 1998 em 14 países, incluindo o Brasil, e indicaram que as diferenças entre demandas previstas e realizadas em projetos rodoviários superam a faixa dos $20 \%$.

Tabela 2

Razão entre demanda prevista e realizada em 2002

\begin{tabular}{|cc|}
\hline Concessionárias & Demanda Prevista/Realizada 2002 \\
\hline Triângulo do Sol & $-43,7 \%$ \\
Centrovias & $-34,3 \%$ \\
Viaoeste & $-32,7 \%$ \\
Ecovias & $-18,8 \%$ \\
Autovias & $-13,5 \%$ \\
Colinas & $-12,2 \%$ \\
Renovias & $-8,8 \%$ \\
Tebe & $-4,4 \%$ \\
Autoban & $3,7 \%$ \\
SPVias & $4,1 \%$ \\
Vianorte & $28,5 \%$ \\
Intervias & $87,9 \%$ \\
\hline
\end{tabular}

Concessionárias marcadas em itálico foram licitadas em 2000, as demais foram licitadas em 1998.

Fonte: Artesp (2006).

Se as estimativas de tráfego realizadas pelo lado público tendem a ser otimistas, seria possível aos licitantes elaborar suas próprias avaliações e realizar propostas mais realistas. Não foi o que se verificou na maior parte das propostas, e existem incentivos para que assim não o façam. Em uma licitação em que será vencedor o proponente que oferece o maior ônus pela outorga dos serviços, ajustar as projeções de demanda para baixo significa reduzir o ônus potencial da proposta e, caso os outros competidores não o façam, perder a chance de um lance vencedor. Como consequência, praticamente todas as propostas de licitantes empregaram as projeções de demanda fornecidas no edital.

Há ainda um incentivo adicional no caso de licitações cujos investimentos terão de ser financiados por bancos de investimentos, sejam eles bancos multilaterais, bancos privados ou o BNDES. Se os proponentes reduzirem as projeções de demanda, dado que a tarifa é definida no edital, haverá redução na geração de caixa, assim os financiadores também reduziriam o 
montante financiável aos operadores, exigindo maior aporte de capital próprio. Bain (2009) avaliou esse efeito em um estudo empírico com uma base de 100 projetos de rodovias pedagiadas obtidos junto a financiadores de projetos. Comparou projeções de demanda com a demanda realizada, concluindo que as demandas apresentam viés de otimismo. Tal situação requer cuidados adicionais da engenharia financeira desse tipo de projeto, que mantenha flexibilidade ante as variações de demanda, mas capazes de garantir a liquidez dos projetos.

Embora os contratos de concessão explicitamente aloquem o risco de tráfego (demanda) ao concessionário, não dando direito a compensações, ao empregar as projeções de demanda de edital as concessionárias acabaram por manter também os cronogramas de obras previstos nos projetos básicos, que teriam de ser cumpridos mesmo em face de receitas inferiores às previstas, constituindo assim uma fonte de potencial conflito. Passemos então à análise da atuação da Artesp em seu papel de fiscalização e monitoramento das concessionárias.

Reguladores podem atuar preventivamente emitindo advertências e, se concessionárias não se movem para sanar falhas, devem aplicar penalidades. A agência exerce sua autoridade no âmbito administrativo, sendo preferível algum tipo de interação que faça valer sua autoridade na gestão do contrato, constituindo uma reputação perante os regulados. O exercício da autoridade administrativa pode ser enfraquecido por aplicação demasiada de multas que podem ser questionadas no Judiciário (Laffont, 2003).

A tabela 3 apresenta um resumo do histórico da atuação da Artesp entre 1999 e 2006 no monitoramento dos contratos perante cada uma das concessionárias. Diante da constatação de desvios em relação ao plano de obras contratado e de desvio de índices de desempenho requeridos, a Artesp emite notificações. Em casos de não atendimento ou correção dos desvios apontados a Artesp aplica multas.

Tabela 3

Notificações e multas aplicadas no período 1999-2006 por concessionária

\begin{tabular}{|ccc|}
\hline Concessionárias & Notificações & Multas \\
\hline SPVias & 210 & 21 \\
Autoban & 172 & 17 \\
Viaoeste & 166 & 21 \\
Vianorte & 152 & 20 \\
Ecovias & 141 & 13 \\
Autovias & 137 & 1 \\
Intervias & 126 & 1 \\
Triângulo do Sol & 115 & 2 \\
Centrovias & 95 & 9 \\
Colinas & 93 & 8 \\
Tebe & 79 & 2 \\
Renovias & 52 & 1 \\
Total & 1538 & 16 \\
\hline
\end{tabular}

Concessionárias marcadas em itálico foram licitadas em 2000, as demais foram licitadas em 1998. Fonte: Artesp (2006). 
Verificou-se que no período foram emitidas 1.538 notificações, 79,19\% desse total emitidas pelas diretorias de investimento (ampliação e conservação) e controle econômico (financeiro), portanto, mais relacionadas aos investimentos que à operação rodoviária propriamente dita. Das notificações aplicadas pela Artesp, 61\% foram acatadas e corrigidas pelas concessionárias, porém 29\% delas foram contestadas pelas concessionárias, e 22,11\% tiveram penalidade de advertência e 7,5\% levaram à aplicação de multa. Em termos absolutos, das 1.538 notificações, apenas 340 tornaram-se advertências e, dessas, 116 resultaram em multas.

A principal razão para aplicação de multas foi exatamente o atraso de compromissos com ampliações, representando 55 das 116 multas. Foram aplicadas 45 multas em decorrência do não atendimento de condições operacionais, oito devido a problemas de conservação e outras oito referentes a aspectos econômico-financeiros. Os atrasos em investimentos podem estar associados à realização de receitas tarifárias abaixo das expectativas dos operadores.

Destaque-se que o caso da SPvias é ilustrativo: trata-se da concessão com maior número de notificações e multas, é também de maior extensão quilométrica e menor índice VDM/km.

Com o entendimento de que a dinâmica de relacionamento entre os agentes se viabiliza por meio de ajustes no decorrer do exercício do contrato, passaremos agora a analisar os ajustes ocorridos.

As alterações nos termos iniciais de um contrato de concessão devem passar por processo de análise no âmbito do poder concedente, avaliada pela procuradoria jurídica do estado, bem como receber apreciação do Tribunal de Contas. Embora a Artesp exerça a função técnica, reunindo competências tanto na análise das condições de execução dos serviços rodoviários como do julgamento da adequação dos impactos econômicos decorrentes de uma renegociação contratual, o ajuste não é aprovado por decisão da agência reguladora.

Caso o ajuste requeira algum recurso orçamentário do estado, ele deverá também ser avaliado pelos órgãos centrais da administração das finanças do estado. Desse modo, o instrumento jurídico associado a um ajuste será um termo aditivo modificativo (TAM) que é publicado em Diário Oficial, formalizando a alteração contratual.

É importante frisar que os ajustes não correspondem necessariamente a pleitos de recomposição de equilíbrio econômico nas circunstâncias previstas em contrato. De fato, entre os TAMs analisados, apenas em um deles consta a expressão reequilíbrio econômico-financeiro. Nesses casos, a Artesp tem autonomia para proceder ao reequilíbrio do contrato. Solicitações de reequilíbrio podem ser aceitas e resolvidas em favor das concessionárias caso as razões do desequilíbrio econômico-financeiro estejam fundamentadas em riscos não assumidos por elas. Os contratos de concessão preveem que, uma vez caracterizado o desequilíbrio, o regulador poderá propor o meio para compensar o concessionário, sendo um ajuste no valor da tarifa, alteração do cronograma de investimentos, prorrogação do período de vigência do contrato de concessão, ou uma combinação desses meios.

A tabela 4 apresenta, como identificados em relatórios elaborados pela Artesp, o total de Termos Aditivos Modificativos celebrados com as concessionárias no período, bem como os pleitos de modificações em análise e ainda não validados à época do levantamento realizado. 
Tabela 4

Quantidade de Termos Aditivos Modificativos por concessionária assinados no período 1999-2006 (acumulado)

\begin{tabular}{|ccc|}
\hline Concessionárias & TAM* validados & $\begin{array}{c}\text { TAM* } \\
\text { em análise }\end{array}$ \\
\hline Colinas & 17 & 2 \\
Autoban & 14 & 2 \\
Triângulo do Sol & 14 & 3 \\
Autovias & 13 & 1 \\
Intervias & 12 & 1 \\
SPVias & 12 & 3 \\
Renovias & 11 & 3 \\
Tebe & 10 & 1 \\
Viaoeste & 9 & 4 \\
Centrovias & 9 & 5 \\
Ecovias & 7 & 4 \\
Vianorte & 6 & \\
* TAM - termo aditivo modificativo & & \\
Concessionárias marcadas em itálico foram licitadas em 2000, as demais foram licitadas \\
em 1998.
\end{tabular}

O grande número de ajustes observados em período tão reduzido requer que se faça uma qualificação sobre a natureza dos ajustes realizados à luz da repartição de riscos estabelecida nos contratos. É importante destacar que todos os pleitos que estavam em análise, destacados na terceira coluna da Tabela 4, tratavam de adequações no cronograma físico-financeiro, que se constitui no principal compromisso das concessionárias.

A Tabela 5 apresenta uma tabulação das razões que suscitaram a celebração e termos modificativos dos contratos. Essas razões foram agrupadas em cinco classes: alterações de controle societário; repasse de ISS; índices de reajuste tarifários não aplicados na data; alterações nas condições iniciais de obrigações contratuais; alterações do cronograma físicofinanceiro do contrato.

Como o contrato de concessão é celebrado com uma empresa de propósito específico, as alterações de controle acionário da empresa devem contar com a anuência do poder concedente, isto é, o poder concedente como controlador do ativo específico, a concessão, se resguarda o direito de interferir nas relações entre os sócios da concessionária. A segunda coluna da tabela 5 apresenta as alterações de controle societário. Nota-se que no período o número de alterações societárias foi relativamente pequeno, representando basicamente a entrada da controladora espanhola OHL no Brasil, por meio de aquisição de controle. Esse tipo de alteração de controle, em que consórcios constituídos por empresas de construção cedem a 
participação para empresas com perfil de operação, é parte do amadurecimento da indústria de concessões em diversos países.

Tabela 5

Tipos de ajustes contratuais realizados, por concessionária, realizados no período 1999-2006 (acumulado)

\begin{tabular}{|cccccc|}
\hline Concessionárias & $\begin{array}{c}\text { Alterações de } \\
\text { Controle Societário }\end{array}$ & $\begin{array}{c}\text { Repasse } \\
\text { de ISS }\end{array}$ & $\begin{array}{c}\text { Índices Não } \\
\text { Aplicados }\end{array}$ & $\begin{array}{c}\text { Inclusões/ } \\
\text { Exclusões } \\
\text { Contratuais }\end{array}$ & $\begin{array}{c}\text { Cronograma } \\
\text { Físico-financeiro }\end{array}$ \\
\hline Autoban & 0 & 3 & 0 & 7 & 4 \\
Autovias & 1 & 3 & 4 & 1 & 4 \\
Centrovias & 2 & 1 & 4 & 0 & 2 \\
Colinas & 3 & 2 & 4 & 6 & 5 \\
Ecovias & 1 & 3 & 4 & 1 & 3 \\
Intervias & 1 & 2 & 4 & 0 & 6 \\
Renovias & 0 & 0 & 4 & 2 & 2 \\
SPVias & 0 & 0 & 3 & 7 & 3 \\
Tebe & 0 & 3 & 4 & 0 & 3 \\
Triângulo do Sol & 0 & 2 & 4 & 5 & 5 \\
Viaoeste & 0 & 0 & 3 & 2 & 2 \\
Vianorte & 0 & 0 & 4 & 0 & 44 \\
Total & 8 & 19 & 42 & 31 & 5 \\
\hline
\end{tabular}

Fonte: Artesp (2006).

O recolhimento de ISS aos municípios lindeiros das concessionárias não estava explicitamente previsto como obrigação contratual nos editais e não foi considerado no fluxo de caixa das propostas. O recolhimento desse imposto deveria ser compensado financeiramente apenas para as concessionárias que iniciaram a cobrança de pedágio sem considerá-lo. $\mathrm{Na}$ terceira coluna da Tabela 5, sob o título Repasse do ISS, observamos o número de ajustes realizados para cada concessionária. Nota-se que nem todas as concessionárias necessitaram desse tipo de ajuste, enquanto outras tiveram até três compensações. A Tabela 6 apresenta distribuição temporal dos ajustes, revelando que esse instrumento de compensação teve importância entre 2000 e 2002.

A quarta coluna da Tabela 5 apresenta os ajustes decorrentes da decisão do governo estadual de autorizar o reajuste tarifário anual abaixo do índice de reajuste contratual em algumas praças de pedágio, especificamente para as rodovias de pista simples. Nota-se que esses ajustes só não tiveram impacto sobre a Autoban, e na Tabela 6 percebe-se que eles se intensificaram a partir de 2002. 
Tabela 6

Distribuição dos ajustes contratuais por ano, realizados no período 1999-2006

\begin{tabular}{|c|c|c|c|c|c|c|}
\hline Ano & $\begin{array}{l}\text { Alterações } \\
\text { de Controle } \\
\text { Societário }\end{array}$ & $\begin{array}{l}\text { Repasse de } \\
\text { ISS }\end{array}$ & $\begin{array}{l}\text { Índices Não } \\
\text { Aplicados }\end{array}$ & $\begin{array}{c}\text { Inclusões/Exclusões } \\
\text { Contratuais }\end{array}$ & $\begin{array}{l}\text { Cronograma } \\
\text { Físico- } \\
\text { financeiro }\end{array}$ & Total Ano \\
\hline 1999 & 0 & 0 & 0 & 0 & 0 & 0 \\
\hline 2000 & 0 & 5 & 0 & 7 & 4 & 16 \\
\hline 2001 & 2 & 7 & 0 & 5 & 11 & 25 \\
\hline 2002 & 2 & 6 & 10 & 7 & 10 & 35 \\
\hline 2003 & 1 & 1 & 11 & 3 & 2 & 18 \\
\hline 2004 & 1 & 0 & 10 & 4 & 4 & 19 \\
\hline 2005 & 1 & 0 & 1 & 3 & 6 & 11 \\
\hline 2006 & 1 & 0 & 10 & 2 & 7 & 20 \\
\hline Total & 8 & 19 & 42 & 31 & 44 & 144 \\
\hline
\end{tabular}

Fonte: Artesp (2006).

É importante destacar que para mitigar os efeitos do repasse do ISS e da não correção de tarifas e repasses pelo indexador contratual sem onerar os usuários foi autorizado o abatimento do ônus devido pela concessionária.

As razões de ajustes até aqui avaliadas podem ser consideradas alheias ao potencial de negociação entre regulado e regulador. Quando considerados os ajustes representados por Inclusões/Exclusões Contratuais (quinta coluna) e Cronograma Físico-financeiro (sexta coluna) da Tabela 5, tais alterações referem-se a circunstâncias em que o regulador tem de exercer o julgamento técnico próprio de sua função.

No item "inclusões e exclusões contratuais", os aspectos de eficiência técnica e defesa do interesse público podem conduzir à transferência de responsabilidade para as concessionárias, como exemplificado pela transferência de manutenção de vias secundárias ou estradas vicinais, portanto não integrantes das concessões, da jurisdição do DER para as concessionárias. Em contrapartida dessa obrigação, as concessionárias receberiam as verbas orçamentárias correspondentes. Um conjunto de obrigações públicas de menor monta foi repassado às concessionárias, tais como desapropriações para realização de obras, cobertura dos custos para obtenção de licenças prévias e projeto ambiental (EIA/Rima). Há ainda uma solicitação para inclusão de trecho rodoviário na área de uma concessão.

A transferência de certas obrigações às concessionárias parece ter sido pautada pela eficácia na solução de pendências que seriam de interesse tanto das concessionárias como do poder concedente. Varias alterações trataram também de realocação de praças de pedágio, implantação de cobrança bidirecional, implantação de pedágio de bloqueio para impedir rotas de fuga das praças de pedágio principal. As considerações das propostas partindo das con- 
cessionárias requeriam avaliação técnica dos efeitos e resultados esperados, contando muitas vezes com a oposição e mesmo com o poder público local.

As alterações de Cronograma Físico-financeiro tratam dos atrasos e antecipações no cronograma previsto em contrato. Não só representam o maior número de alterações como também foram objeto de maior incidência de advertências e multas aplicadas pela Artesp. O não cumprimento de prazos das ampliações foi um dos principais pontos polêmicos. A postergação de desembolsos associados ao cronograma de obras é um instrumento de controle da rentabilidade de uma concessionária. Sem uma fiscalização efetiva por parte da agência, a concessionária pode gerenciar seus resultados alegando que fatores externos impedem o cumprimento do cronograma de obras. No sentido contrário, os cronogramas de execução contratuais impedem também a pressão política por antecipações de calendário político de inaugurações. A gestão técnica do cronograma de obras e da equação econômico-financeira do contrato constitui boas razões para a delegação do controle desses compromissos em mão de uma agência tecnicamente afeita a essa função.

Na Tabela 6 observa-se que, para um período de sete anos, todas as concessionárias tiveram repactuações do cronograma de execução de obras, destacando-se Renovias, que passou por seis revisões; Colinas e Intervias, que tiveram cinco alterações, e Autovias e Autoban, com quatro alterações. A análise da magnitude desses ajustes não foi objeto deste trabalho, cabendo registrar que o uso desse mecanismo de governança permitiu a adaptação contratual a um cronograma de obras previsto pelo poder concedente.

Há um cenário que pode ter facilitado o uso desse mecanismo. Os cronogramas de obras consideravam, além das obras iniciais de adequação aos níveis de serviço definido no contrato, a realização de obras compatíveis com as projeções de demanda. Se as projeções se demonstrassem muito otimistas, certas obras de ampliação poderiam ser adiadas sem prejuízo da qualidade dos serviços. Se, por outro lado, as projeções fossem muito pessimistas, o cronograma previsto em edital seria insuficiente para atender os níveis de serviço esperados.

No processo licitatório as concessionárias tinham liberdade para adotar suas próprias projeções de demanda e ajustar o cronograma de obras de acordo com suas estimativas. Como regra, as concessionárias preferiram aderir às projeções e manter o cronograma previsto em edital, mantendo a disputa em relação ao ônus pago. Isso não alteraria a condição de que os riscos de variação de demanda fossem assumidos pelas concessionárias, impedindo que a frustração da demanda prevista fosse utilizada como base para pleitos de reequilíbrio econômico-financeiro. Se tudo mais permanecesse constante, os cronogramas iniciais teriam de ser cumpridos, mesmo diante de demandas mais baixas que as previstas e, diante de demandas mais altas que as previstas, certas obras deveriam ser antecipadas para cumprir obrigações de nível de serviço.

Na Tabela 6 é possível constatar que 25 das 44 revisões de cronograma ocorreram até o ano de 2002. Comparando essa informação com os dados de demanda apresentados na Tabela 2 , a razão entre demanda prevista e demanda realizada no ano de 2002, nota-se que oito concessionárias encontravam demanda menor que a prevista, com destaque para Triângulo do Sol, Centrovias e Viaoeste, com valores de demanda esperados superiores em 30\% ao realizado. 
É pertinente mencionar que no caso da Intervias, que apresentou demanda 89,7\% superior à prevista, a primeira licitação desse lote não atraiu proponentes em função de dificuldade de operacionalização das praças de pedágio. Superados alguns problemas de rota de fuga, o lote foi novamente licitado empregando o estudo de demanda original.

Pode-se inferir, portanto, que ao adotarem em seus Planos de Negócio previsões de demanda e cronogramas de obras elaborados pelo poder concedente, as concessionárias partiram de uma base comum para formular suas propostas no processo de licitação. Ao empregar essa base comum na mensuração de eventos fora de seu controle, mas cujos riscos lhes foram contratualmente atribuídos, poderiam empregá-la de forma consistente em eventuais negociações quanto à frustração de demandas.

Pode-se adicionar que circunstâncias técnicas, sociais e políticas teriam dificultado a cobrança de tarifas mesmo em praças de pedágio existentes. No caso das praças que efetuavam a cobrança numa única direção, incentivava o uso de rotas alternativas. Boa parte das Inclusões e Exclusões Contratuais e Adequações dos Cronogramas Físico-financeiros esteve associada ao processo de aperfeiçoamento da implantação eficiente dos pedágios. A despeito de erros nas projeções de demanda, os sistemas de cobrança da demanda existentes requeriam alterações que precisavam ser avaliadas e validadas pelo poder concedente e pela Artesp, após a sua instituição. Esses ajustes visavam o imediato aumento da arrecadação, tendo como virtude tornar o sistema de cobrança mais eficiente e equitativo para os usuários, e produziram efeitos sobre o equilíbrio econômico-financeiro dos contratos.

\section{Considerações finais}

A agenda de modernização do Estado brasileiro que foi implantada na segunda metade dos anos 1990 tem como resultado um desenho institucional de concessões de serviços públicos exploradas por investidores privados, que se encarregaram do financiamento e execução de projetos de infraestrutura de longo prazo de maturação, já envolvendo vários mandatos governamentais. Para a continuidade de sucesso se requerem regras estáveis e consistentes. As agências reguladoras foram concebidas para cumprir esse papel relevante, no âmbito do estado, garantindo um relacionamento público-privado fundamentado no interesse público.

A Artesp foi criada em 2002 para, entre outras atribuições, regular o programa de concessões rodoviárias do estado de São Paulo, constituído inicialmente por 12 contratos de concessão, licitados entre 1998 e 2000. Este trabalho analisou vários dos relatórios de acompanhamento das concessões produzidos pela Artesp, procurando compreender sua atuação fiscalizadora (notificações e multas) e reguladora (ajustes contratuais), em particular pelo enfoque da literatura de contratos incompletos.

A atuação de fiscalização é bem estruturada, contando com o apoio de empresas especializadas. Verificou-se forte presença junto às concessionárias, com mais de 1.500 notificações, principalmente no que se referiu à ampliação e conservação, e as multas aplicadas também se concentraram nesses objetos. 
As renegociações encontradas não alteraram os termos gerais do contrato, mas trataram de alterações no cronograma de obras e eventuais acréscimos de obras não previstas no programa original. As alterações nos termos contratuais foram pautadas pela preservação do equilíbrio financeiro inicial do contrato. A análise dos ajustes ocorridos no processo de interação entre Artesp e concessionárias de rodovias permite concluir pela existência de uma dinâmica produtiva entre regulador e regulados, com a superação de eventos e circunstâncias não previstos por meio da adaptação das condições contratuais, Termos Aditivos Modificativos, que conduziram à viabilização de uma indústria saudável de concessões rodoviárias no estado de São Paulo.

Até 2006 a principal ferramenta para o reequilíbrio dos contratos foi o deslocamento do cronograma de obra. Os principais investimentos já haviam sido realizados, restando ainda investimentos em manutenção e conservação especial, que não eram passíveis de postergação. Ainda, a utilização do ônus comprometeria o orçamento do DER afetando suas próprias atividades.

Para sanar os pleitos que ainda estavam pendentes, a medida adotada pela Artesp para reequilibrar os contratos foi a prorrogação de prazo. Essa foi a saída encontrada pela Artesp para atender ao governo e às concessionárias. A manutenção da TIR contratada durante o prazo prorrogado da concessão proporcionaria ao concessionário um ganho anormal, posto que a TIR contratada em 1998 (superior a 17\% ao ano) era muito maior que o custo médio de capital na época da decisão de prorrogação dos prazos das concessões (aproximadamente $10 \%$ ao ano). De modo que a simples prorrogação do prazo com a manutenção da TIR contratada não permitiria a observância, por parte da Artesp, do princípio constitucional da modicidade tarifária.

Cabe ressaltar ainda que, se por um lado o atual modelo de concessão foi bem-sucedido na implantação de um sistema rodoviário eficiente, sua concepção não incentiva a promoção da modicidade tarifária. O aperfeiçoamento do modelo de tarifação, bem como outros estímulos que induzam a redução dos custos dos serviços, necessita ser incorporado.

\section{Referências}

ARTESP. Documento interno da Agência Reguladora de Serviços Públicos Delegados de Transporte do Estado de São Paulo. São Paulo, 2006.

BAIN, Robert. Error and optimism bias in toll road traffic forecasts. Transportation: Planning, Policy, Research, Practice, v. 36, n. 5, p. 469-482, 2009.

BESANKO, David et al. A economia da estratégia. Porto Alegre: Bookman, 2006.

BNDES. As concessões rodoviárias no país. Cadernos de Infraestrutura, Rio de Janeiro, 2001. Disponível em: <http://www.bndes.gov.br/conhecimento/cadernos/cad-17.pdf>. Acesso em: 28 set. 2006. 
BRASIL. Lei no 7.712, de 22 de dezembro de 1988. Disponível em: < http://www.presidencia.gov. br/legislacao/>. Acesso em: 3 maio 2012.

BRASIL. Lei nº 8.075, de 16 de agosto de 1990. Disponível em: <http://www.presidencia.gov.br/ legislacao/>. Acesso em: 3 maio 2012.

BRESSER-PEREIRA, Luiz Carlos; GRAU, Nuria Cunill. Entre o Estado e o mercado: o público não estatal. In: BRESSER-PEREIRA, Luiz Carlos; GRAU, Nuria Cunill (Org.). O público não estatal na reforma do Estado. Rio de Janeiro: Editora FGV, 1999. p. 15-48.

BRINKERHOFF, Jennifer M.; BRINKERHOFF, Derick W. Government-nonprofit relations in comparative perspective: evolution, themes and new directions. Public Administration and Development, v. 22, n. 1, p. 3-18, 2002.

BROUSSEAU, Eric; FARES, M'hand. Incomplete contracts and governance structures. In: MÉNARD, C. (Ed.). Institutions, contracts, organizations, perspectives from new-institutional economics. Cheltenham: Edward Elgar, 2000.

FLYVBJERG, Bent; HOLM, Mette K. S.; BUHL, Soren L. How (in)accurate are demand forecasts in public works projects? Journal of the American Planning Association, v. 71, n. 2, 2005.

FURUBOTN, G. Eirik; RICHTER, Rudolf. Institutions economics and economic theory: the contribution of the new institutional economics. Michigan: Michigan Press, 2000.

GOVERNO DO ESTADO DE SÃO PAULO. Edital de licitação do programa estadual de desestatização e parcerias com a iniciativa privada, 2003. Disponível em: <www.artesp.sp.gov.br/biblioteca/biblio_editais.asp>. Acesso em: 28 set. 2006.

GOVERNO DO ESTADO DE SÃO PAULO. Lei $n^{\circ}$ 9.361, de 5 de julho de 1996. Disponível em: <www. impresaoficial.com.br/>. Acesso em: 8 nov. 2011.

GREIF, Avner. Commitment, coercion, and markets: the nature and dynamics of institutions supporting exchange. In: MÉNARD, Claude; SHIRLEY, Mary M. (Ed.). Handbook of new institutional economics. Nova York: Springer, 2005.

GUASCH, J. Luis. Granting and renegotiating infrastructure concessions. The World Bank. 2004. Disponível em: <http://books.google.com/books?hl=pt-BR\&lr=\&id=xBqtbaBM-Z0C\&oi=fnd\&p

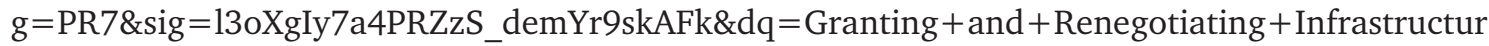
e+Concessions $>$. Acesso em: 28 set. 2006.

HART, Oliver; MOORE, John. Incomplete contracts and renegotiation. Econometrica, v. 56, n. 4, p. 755-785, 1988.

KLEIN, Peter G. New institutional economics. University of Georgia; Department of Economics, 1999.

LAFFONT, Jean J. Enforcement, regulation and development. Journal of African Economies, v. 12, p. ii193-ii211, 2003.

MARTIMORT, David. The life cycle of regulatory agencies: dynamic capture and transaction costs. The Review of Economic Studies, v. 66, p. 929-947, 1999. 
MELLO, Maria Tereza L.; ANUATTI, Francisco. Arbitragem e risco regulatório em contratos de concessão. In: SEMINÁRIO BRASILEIRO DA NOVA ECONOMIA INSTITUCIONAL, II, 2001, Campinas. Anais... Campinas, 2001.

MILGRON, Paul. R.; ROBERTS, John. Economics, organization and management. New Jersey: Prentice-Hall, 1992.

MONTEIRO, R. F. O equilíbrio econômico-financeiro dos contratos de concessão. Revista Engenharia, São Paulo, v. 63, n. 572, p. 171-175, 2005.

OLIVEIRA, Miguel D.; TANDON, Rajesh. Citizens: strengthening global civil society. Washington, DC: Civicus, 1994.

OLIVEIRA, Roberto G.; MICHEL, Fernando D.; CYDIS, Helena B. B. (Org.). A experiência brasileira de concessões de rodovias. São Paulo: Fundação Instituto de Pesquisas Econômicas (Fipe-USP); Laboratório de Sistemas de Transportes (Lastran-UFRGS), 2004.

PAULA, Ana P. P. Por uma nova gestão pública. Rio de Janeiro: FGV, 2005.

RECCHI, W. Contrato de concessão rodoviária: recente história. Revista Engenharia, São Paulo, v. 63, n. 572, p. 106-108, 2005.

SELSKY, John; PARKER, Barbara. Cross-sector partnerships to address social issues: challenges to theory and practice. Journal of Management, v. 31, n. 6, p. 849-873, 2005.

STERN, Jon. Regulation and contracts for utility services: substitutes or complements? Lessons from UK Railway and electricity history? The Journal of Policy Reform, v. 6, n. 4, p. 193-215, 2003.

TIROLE, Jean. Incomplete contracts: where do we stand? Econometrica, v. 67, p. 741-781, 1999.

WILLIAMSON, Oliver E. Comparative economic organization: the analysis of discrete structural alternatives. Administrative Science Quarterly, v. 36, n. 2, p. 269-296, 1991.

Adriana Bortolon Carvalho Cardoso é professora assistente da Faculdade Estácio de Sá de Vitória (Fesv). E-mail: bortolon@live.estacio.br.

André Carlos Busanelli de Aquino é professor associado da Faculdade de Economia, Administração e Contabilidade de Ribeirão Preto (Fearp/USP).E-mail: aaquino@usp.br.

Francisco Anuatti Neto é professor doutor da Fearp/USP. E-mail: fanuatti@usp.br.

Ricardo Lopes Cardoso é professor adjunto da Escola Brasileira de Administração Pública e de Empresas da Fundação Getulio Vargas (Ebape/FGV). E-mail: ricardo.lopes.cardoso@fgv.br. 
